\title{
Las terrazas agrícolas del Sauz Sabino, Hidalgo: 1850-2015
}

\author{
The Agricultural Terraces of Sauz Sabino, Hidalgo: 1850-2015
}

\section{Ignacio Gutiérrez Ruvalcaba*}

INVESTIGADOR INDEPENDIENTE, eljilotillo@gmail.com

El artículo contiene los resultados de una investigación que presenta la manera como un grupo de campesinos de los ejidos del Sauz Sabino, municipio de Atotonilco el Grande, estado de Hidalgo, realizan distintas actividades para producir el sustento mínimo necesario a partir de la construcción de terrazas agrícolas. Las condiciones inhóspitas del área que ocupa el ejido han hecho que terrazas de barranca y ladera sean la única posibilidad para que puedan cultivar su milpa, en un contexto histórico en el que recuperan técnicas de sus antepasados a raíz de los cambios sociales que devienen con la Reforma Agraria del siglo pasado.

PALABRAS CLAVE: terrazas agrícolas, formación de suelos, pozos de agua, reforma agraria.

This article presents the results of a research project that reveals how a group of peasants from the ejidos of Sauz Sabino, municipality of Atotonilco el Grande, state of Hidalgo, perform different activities in order to produce the minimum necessary sustenance through the construction of agricultural terraces. The inhospitable conditions of the lands that these ejidos occupy have made terraces on ravines and hillsides their only option for cultivating corn. Interestingly, this process finds them rescuing techniques used long ago by their ancestors that reflect the social changes triggered by Mexico's Agrarian Reform programs implemented in the last century.

KEYWORDS: agricultural terraces, soil formation, water wells, agrarian reform.

Fecha de recepción: 20 de enero de 2016 / Fecha de aceptación: 8 de marzo de 2016 / Fecha de versión definitiva: 14 de marzo de 2016

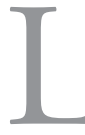

a Reforma Agraria, comenzada con el decreto de ley de Dotaciones y Restituciones del 6 de enero de 1915, dio lugar no sólo a la obtención de tierras por parte de una infinidad de pueblos, rancherías y congregaciones a lo largo y ancho del país,

* El autor agradece a los árbitros por sus comentarios y sugerencias, los cuales han sido integrados al texto en su mayor parte. 
sino también como consecuencia quizás inesperada por quienes instrumentaron dicha política, la recuperación de prácticas agrícolas, tocante al manejo de recursos naturales cuyo origen era ancestral, parte de una tradición que permitió a muchos campesinos, indígenas y mestizos hacer productivas sus parcelas y obtener su sustento. El estudio de las terrazas de barranca-conocidas en distintas partes del país como cajetes, jollas, lama-bordo, camellones- de la población del Sauz Sabino, en el municipio de Atotonilco el Grande, estado de Hidalgo, es un caso representativo para ver la recuperación de un saber a partir de la constitución de su ejido en el año de 1924. De igual forma permitirá advertir un conjunto de conocimientos y habilidades que estos pobladores tienen, por medio de un estudio de caso, donde la formación de suelo agrícola, el aprovechamiento de agua y el manejo de la milpa dan lugar a una estrategia de producción campesina. ${ }^{1}$

\section{UN PASADO NO MUY LEJANO ${ }^{2}$}

Los pobladores de Sauz Sabino, cuyos antepasados, aquellos que tramitaron la dotación de tierras para formar el ejido entre la segunda y tercera décadas del siglo pasado, padres de los actuales abuelos que eran hablantes de la lengua otomí o hñänu, tienen una historia que comparten con otros ejidos del municipio de Atotonilco el Grande y otras muchas partes del país. El origen de estos ejidos se encuentra en la formación de un gran latifundio cuyas raíces se remontan al siglo XVI, denominado como la hacienda de San Nicolás Amajac, dedicada a la explotación agrícola y a la cría de ganado caprino que, a mediados del siglo xIx, se dividió en dos: una nombrada San Nicolás Zoquital y otra San José. ${ }^{3}$

${ }^{1}$ La idea de que la Reforma Agraria dio lugar a la revitalización de prácticas y saberes agrícolas la escuche del Dr. Rafael Ortega Paczka, investigador y profesor de la Universidad Autónoma Chapingo, en junio de 2012.

${ }^{2}$ Las entrevistas realizadas para esta sección se hicieron entre diciembre de 2013 y septiembre de 2014.

${ }^{3}$ Víctor Manuel Ballesteros G., "La hacienda de San Nicolás Amajac del siglo XvI al xx", en Origen y evolución de la hacienda en México, ed., María Teresa Jarquín (Toluca: El Colegio Mexiquense, 1990), 83. 
La hacienda del Zoquital, como se le conoció más comúnmente a la de San Nicolás, al momento de formar una nueva unidad productiva y territorial sufrió una severa crisis económica producto de la mala administración y de los préstamos forzosos en aquellos ańos convulsos para el agro mexicano y, en particular, por la demanda de circulante de las fuerzas juaristas durante la Intervención Francesa. De igual manera fue presionada por algunas poblaciones campesinas de origen hñäñu que demandaban sus derechos sobre tierras que fueron arrebatados cuando aún existía la antigua hacienda de San Nicolás Amajac. Junto a esto, la región, y buena parte de lo que hoy es el estado de Hidalgo, padeció de una serie de rebeliones campesinas que se convirtieron en un fenómeno crónico durante varias décadas. En 1877, un grupo de pronunciados en la cabecera de Atotonilco el Grande impuso a todas las haciendas del rumbo un impuesto que orilló a la del Zoquital a declararse en banca rota en cuanto al pago de las contribuciones estatales. ${ }^{4}$

Esta adversidad la aprovecho el general Rafael Cravioto, gobernador entonces del estado, para presionar el cumplimiento de sus obligaciones fiscales a los dueńos y administrador de la hacienda. Ante tal circunstancia, el administrador Agustín Mont, con la anuencia de los dueños, ofreció al gobernador la venta del latifundio a manera de pago de impuestos, quien aceptó y, aprovechando su posición, la deuda con el erario se canceló por la petición del jefe de gobierno estatal a la legislatura local. Pero esta compra simulada no fue suficiente para la ambición del señor Cravioto; años más adelante, entre 1894 y 1895, los pueblos de Santa María Amajac, San Nicolás Ayotengo, Sanctórum, San Nicolás Xathé y Cerro Colorado, se quejaron del despojo de tierras por parte del latifundio. En 1900 se llegó al acuerdo de que parte de las tierras serían devueltas; sin embargo, esto sólo fue una promesa que se convirtió en palabra muerta ya que no se cumplió en ningún momento. ${ }^{5}$

${ }_{4}^{4}$ Arturo Herrera Cabañas, Los movimientos campesinos en el Estado de Hidalgo, 1850 -1876 (Pachuca: Gobierno del Estado de Hidalgo, 1995), 101-108; Javier Hernández Mogica, Organización campesina y lucha agraria en el Estado de Hidalgo, 1917-1940 (Pachuca: Universidad Autónoma del Estado de Hidalgo, 2000), 35 y 42.

${ }^{5}$ Hernández Mogica, Organización campesina, 43. 
La Revolución mexicana fue detonante para que las cosas comenzaran a cambiar. La promulgación de la Ley de Dotaciones y Restituciones del 6 de enero de 1915, hecha por Venustiano Carranza, motivó al general Nicolás Flores, gobernador provisional del Estado, el 24 de abril, a formar la primera Comisión Local Agraria. Luego, también el gobernador provisional Alfredo J. Machuca, autorizó el tramite de la petición de los pueblos de San Nicolás Ayotengo, Santa María Amajac, Tizahuapan y San Lucas, del municipio de Atotonilco el Grande, afectados por la Hacienda del Zoquital, a ser restituidos de sus tierras en el mes de mayo, como parte de esta nueva condición emanada de las exigencias agrarias que el movimiento revolucionario había desencadenado. ${ }^{6}$

En 1917, otras poblaciones del municipio al notar que las peticiones de sus vecinos prosperaron, iniciaron los trámites correspondientes para solicitar la restitución de sus tierras. En muchos casos, la situación se complicó debido a que el delegado de la Comisión Local Agraria pudo constatar que dichos pueblos no existían formalmente, por lo que solicitó refundaran la comunidad e iniciaran la petición de dotación. Fue así que nuevamente el general Nicolás Flores, ahora gobernador constitucional, autorizó la creación de los pueblos de Cerro Colorado y San Nicolás Xathé en $1921 .^{7}$

Con esta lógica, un grupo de trabajadores de la hacienda del Zoquital dedicados durante varias generaciones al pastoreo de cabras en un paraje denominado El Sauz, al oeste del casco del emporio agrícola y del otro lado de unos cerros conocidos como Lomas del Zoquital, decidieron promover la dotación de tierras para establecer un ejido el 14 de marzo de 1919 en el paraje conocido como El Sabino. ${ }^{8}$ Estos antiguos trabajadores tenían vínculos familiares con habitantes del pueblo de San Nicolás Xathé, pero su trabajo en la hacienda los obligó a vivir en este sitio inhóspito, entre cerros áridos con poca vegetación, casi sin agua, ganando apenas 30 centa-

${ }^{6}$ Ibid., 53.

${ }^{7}$ Ibid., 88.

${ }^{8}$ Refieren los habitantes del ejido del Sauz Sabino que la crianza de cabras en estos parajes se remonta al tiempo de la que llaman Hacienda Grande, es decir, la de San Nicolás Amajac. 
vos diarios más su ración de maíz, y con derecho de explotar la palma que crece de forma natural por esos rumbos para que elaboraran petates, muy solicitados entonces para usarlos como envoltorios para el trasporte de carga. ${ }^{9}$ Por resolución presidencial del 23 de octubre de 1924, siendo gobernador Amado Azuara y presidente de la nación Álvaro Obregón, se otorgó la dotación definitiva al ejido del rancho de El Sabino con un total de 1,470 ha. ${ }^{10}$ En ese momento, el número de capacitados para recibir tierras fue de 40 individuos, algunos fueron pastores trabajadores de la hacienda del Zoquital, otros eran parientes de éstos, quienes al ser excluidos del reparto de tierras de la población de San Nicolás Xathé, se trasladaron a vivir a la naciente población del Sauz Sabino. ${ }^{11}$

En esta población, junto con las aquí mencionadas y otras más en el municipio, por sus pretensiones para obtener tierras se provocaron conflictos y tensiones con los dueños de la hacienda del Zoquital. La familia Cravioto hizo todo lo posible para que esto no se llevara a cabo; impidieron los trabajos al representante de la Comisión Local Agraria en lo que se refiere a la elaboración de los mapas para los deslindes; endurecieron las condiciones de trabajo en la hacienda; denunciaron a trabajadores, parientes y líderes de los distintos pueblos que pretendían formar su ejidos de robo, homicidio, quema de cosechas, destrucción de equipo agrícola, muerte de ganado, lesiones y despojos ante la autoridad municipal coludida con los Cravioto. Finalmente, los tiempos de la historia se impusieron y los dueños del antiguo latifundio asumieron su situación y destino. ${ }^{12}$

${ }^{9}$ Entrevista con el señor Nicanor González, de 79 años, habitante de la población del Sauz Sabino, quien refiere esta historia en la que participaron su abuelo y padre. La palma (Brahea dulces) con la que hasta la actualidad hacen petates, aventadores y las ofrendas para la bendición del Domingo de Ramos, que venden por muchos pueblos de la región, sobre todo, en los de la denominada Sierra Alta al norte del municipio en el corazón de la Sierra Madre Oriental.

${ }^{10}$ Periódico Oficial del Gobierno del Estado de Hidalgo, 24 de octubre de 1924 y Diario Oficial de la Federación, 24 de octubre de 1924.

${ }^{11}$ Entrevista con el señor Florencio González, de 74 ańos.

${ }^{12}$ Entrevista con el señor Nicanor González. Javier Hernández Mogica, Organización campesina, 88-89. En el Archivo Histórico del Poder Judicial del estado de Hidalgo, en la sección correspondiente al distrito de Atotonilco el Grande, ramo criminal, se puede constatar que entre 1916 y 1924 abundan las denuncias por parte de la familia Cra- 
El 14 de enero de 1926, al sumarse a esta población otros 23 nuevos habitantes, se hizo una petición ante la Comisión Local Agraria y el gobernador para solicitar la ampliación del ejido. Ésta fue aceptada, pero tuvieron que transcurrir doce ańos, como resultado de cambios en la voluntad política por resolver el problema agrario no sólo en el estado, sino también en la nación. ${ }^{13} \mathrm{El} 23$ de marzo de 1938 se otorga por resolución presidencial dada por el presidente Lázaro Cárdenas, la ampliación ejidal con 840 hectáreas nuevas, todas de "terrenos cerriles, monte bajo sólo apto para pastoreo". ${ }^{14}$

La calidad de las tierras y al aumento natural de la población en el ejido hizo que estos terrenos nunca fueran suficientes para las necesidades básicas de sus pobladores, en tanto que en ambas dotaciones no se otorgó ni siquiera una hectárea considerada como agrícola, debido a que la visión técnica hecha por la Comisión Agraria consideró el núcleo agrario como una unidad que debería dedicarse a la ganadería extensiva. Por escrito con fecha del 25 de julio de 1938, nuevamente los habitantes del Sauz Sabino se dirigieron al gobernador para solicitar la ampliación de su ejido con la esperanza de que, con un nuevo reparto también viniese asistencia técnica para desarrollar la ganadería en esas ásperas tierras. ${ }^{15} \mathrm{La}$ Comisión Agraria Mixta realizó el censo el 6 de septiembre de 1940, sumando un total de 93 capacitados. De éstos, 63 ya contaban con el beneficio de la dotación de tierras por lo que sólo 30 eran susceptibles de ser favorecidos con la nueva ampliación. Luego de trascurrir otros doce años, la Comisión Agraria Mixta emitió su dictamen a favor el 7 de septiembre de 1950 para solicitarle al gobernador Vicente Aguirre del Castillo su fallo, que confirmó el 16 de octubre del mismo año.

vioto en contra de pobladores de las distintas poblaciones que, a la postre, fueron beneficiadas con ejidos.

${ }^{13}$ Hernández Mogica, Organización campesina, 119-127.

${ }^{14}$ Diario Oficial de la Federación, 23 de marzo de 1938. Entrevista con el señor Nicanor González. Según la Ley de Dotaciones y Restituciones de Tierras y Aguas del 21 de marzo de 1920, en su capítulo II, artículo 14, fracción III, se indica que en aquellos núcleos agrarios que el censo arroje un número menor a 20 individuos con derecho a tierras no se les podrá dotar: Julio Cuadros Caldas, Catecismo agrario (México: Registro Agrario Nacional, Archivo General Agrario, Ciesas, 1999), 85.

${ }^{15}$ Entrevista con el señor Salvador Jarillo de 78 años. 
Sin embargo, el Cuerpo Consultivo Agrario pese a reconocer que "30 campesinos con capacidad agraria cuyas necesidades agrícolas no han sido satisfechas" consideró que, al no existir en un radio de $7 \mathrm{~km}$ tierras susceptibles de afectación, "debe negarse la ampliación en definitiva y dejarse a salvo los derechos de los capacitados". ${ }^{16}$

Así, con la paciencia de gente acostumbrada a ver que la justicia tarda años, nuevamente solicitaron el 28 de noviembre de 1951 la segunda ampliación de su ejido. La Comisión Agraria Mixta otorgó el visto bueno a la petición y, el 24 de diciembre de ese año, se elaboró el censo y se determinó que ahora eran 40 los capacitados, en tanto se iniciaban los trabajos técnicos para localizar los predios por ser afectados. El dictamen de la Comisión Agraria Mixta lo emitió 16 años después, el 30 de marzo de 1967. El 3 de abril de ese mismo ańo, el gobernador Carlos Ramírez Guerrero declaró procedente el procedimiento, pero negó el otorgamiento de la ampliación ejidal por la falta de fincas afectables en un radio de $7 \mathrm{~km}$, que ratificó el Cuerpo Consultivo Agrario el 24 de septiembre de 1969. ${ }^{17}$ Nuevamente, la espera y la ilusión tenía que imponerse en tanto los políticos en tiempos de elecciones seguían prometiendo justicia "llenándonos con palabras las orejas", ya que "tierras si había y de ello el candidato se hará cargo". ${ }^{18}$

Con el tiempo nacen y mueren pobladores del ejido del Sauz Sabino y algunos abandonan los terrenos debido a las condiciones difíciles del medio natural. También los derechos sucesorios sobre explotación agraria cambian y el conflicto dentro y entre familias nace cuando algunos de sus miembros parten a otros lugares para buscar mejores oportunidades. Los que quedan codician lo abandonado y promueven en las asambleas del ejido cambios en la posesión que, a la larga, son dinamita entre padres, hijos, hermanos y vecinos. Así, por asamblea ejidal del 23 de junio de 1975 se determina solicitar a la Comisión Agraria Mixta la privación de derechos agrarios a un total de 44 pobladores por no haber cultivado sus tierras en un

${ }^{16}$ Diario Oficial de la Federación, 26 de septiembre de 1951.

${ }^{17}$ Diario Oficial de la Federación, 4 de diciembre de 1969.

${ }^{18}$ Entrevista con los seńores Nicanor González, Salvador Jarillo y con el señor Esteban Aldama, este último de 73 ańos. 
periodo consecutivo de dos ańos, junto con sus derechos de sucesión. En cambio se determina entregar estas tierras a un total de 46 habitantes. La Comisión Agraria Mixta establece su procedencia y avala el procedimiento el 6 de agosto de $1976 .{ }^{19}$

Ciertamente, la mayoría de los 44 pobladores enlistados salieron para nunca volver, otros, en cambio, conservan sus raíces familiares y sus pretensiones sobre la tierra también, pero al no entender la ley o no quererla comprender, el ofuscamiento y el encono genera odio y división. Esto ocasiona hechos de sangre, pleitos entre vecinos y familiares que han terminado con la intervención de las autoridades, encarcelamientos y demandas judiciales. ${ }^{20}$

Esta historia de privación de derechos a los ausentes y reconocimiento a otros se repite en 1981, retiran sus prerrogativas a 53 pobladores, debido a su ausencia y entregan parte de estas tierras a otros once, el 16 de marzo de $1981 .{ }^{21}$ La diferencia tan marcada que existe en cuanto a los beneficiados, se explica por un reacomodo entre las familias habitantes del ejido donde, luego de una negociación interna en el reparto, entre padres, hijos, sobrinos, nueras y yernos, en el marco de la asamblea ejidal, sólo hubo cabida a los once habitantes que efectivamente no contaban con tierras. ${ }^{22}$

Los pobladores del ejido del Sauz Sabino, desde que se constituyó como una población en 1924, formaron una comunidad donde todos se reconocen. Eran parientes o compańeros en la lucha por la subsistencia que, al formar el núcleo agrario, se asumían como iguales, donde los vínculos de sangre y las relaciones simbólicas de compadrazgo provocaron cohesión. El trabajo entre familiares, la celebraciones del ciclo de vida como los nacimientos, quince ańos, matrimonios y defunciones, estrecharon los lazos y la identidad de los pobladores, y más cuando en el año de 1942 se edificó la capilla del culto católico que dio pauta a que los ritos locales se consolidaran, sin la necesidad de salir a la vecina población de Santa María

${ }^{19}$ Diario Oficial de la Federación, 28 de septiembre de 1976.

${ }^{20}$ Entrevistas con los señores Cayetano Jarillo de 76 años, y con el señor Maximino González de 79 años.

${ }^{21}$ Diario Oficial de la Federación, 1 de junio de 1981.

${ }^{22}$ Entrevista con el señor Salvador Jarillo. 
Mapa. Ubicación del ejido del Sauz Sabino

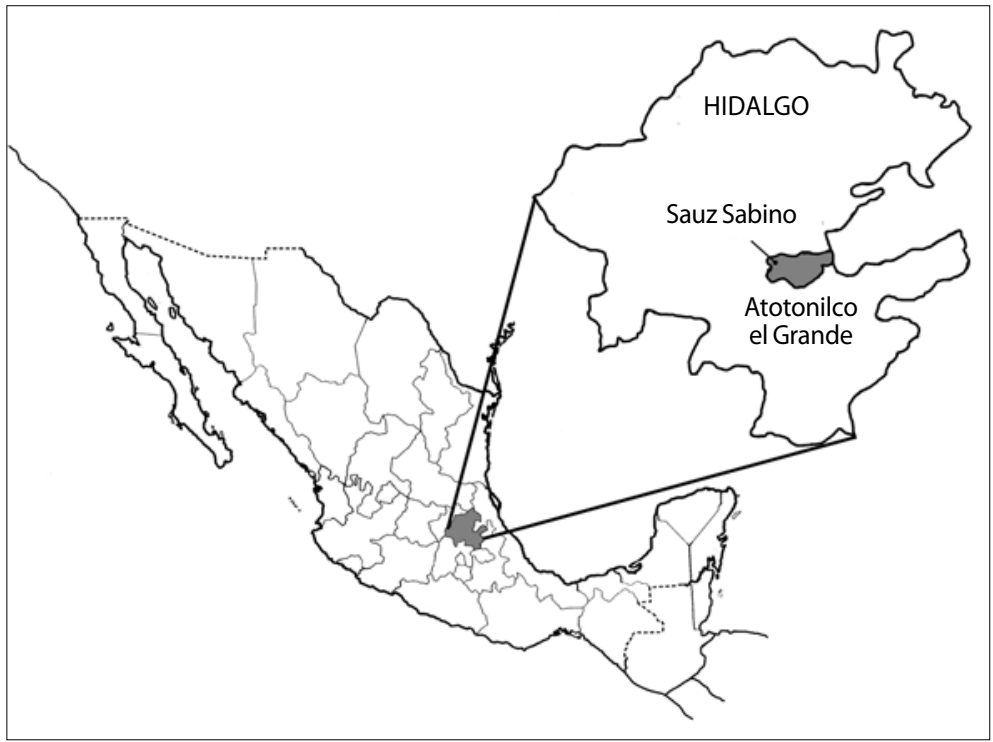

Amajac, a la cabecera municipal o a las celebraciones religiosas efectuadas en la capilla de la antigua hacienda del Zoquital, viejo símbolo de la opresión.

En 1957 se construye la primera escuela primaria, hecha con materiales locales con apenas dos salones, una habitación para el maestro, asta bandera y una letrina, edificio evocador de una institución que ayudó a que la juventud local adquiriera los conocimientos básicos para la vida social en la misma comunidad. El medio saber leer y escribir también ayudó a tener confianza para buscar mejores horizontes, más allá de los cerros que veían sus ojos; es decir, la misma educación escolar sentó las bases para que algunos jóvenes al crecer tuvieran la entereza suficiente para aventurar su vida fuera de la población donde nacieron. ${ }^{23}$

${ }^{23}$ Entrevistas con los señores Cayetano Jarillo y Maximino González. Entrevista con el señor Pablo González de 68 años, señoras Herminia Aldama de 71 ańos y Juana González de 75 años. 
La población de Sauz Sabino y sus dos barrios se ubican entre cerros y lomas que son parte de un brazo que se desprende del Eje Neovolcánico que atraviesa buena parte del estado de Hidalgo y, precisamente, esta parte del municipio de Atotonilco el Grande junto con el de Actopan se une con la Sierra Madre Oriental. Al este del municipio corre la profunda barranca del río Grande de Tulancingo o Metztitlán, mientras que al oeste serpentea la barranca el río Amajac. Ambos son parte de la cuenca del río Moctezuma-Pánuco.

El municipio de Atotonilco el Grande cuenta con variados microambientes determinados por la altitud, las sombra pluvial que sobre sus tierras provoca la Sierra Madre y el hecho de ser un territorio donde se combinan montańas, barrancas, llanuras y lomeríos. Es decir, al tener al sur y oeste el Eje Neovolcánico y al norte y este la Sierra Madre Oriental, la temperatura, precipitación, tipos de suelo y topografía varían mucho en distancias muy cortas.

La zona donde se localizan las tierras de Sauz Sabino son parte de uno de los varios microambientes con una altitud media de 1957 msnm. ${ }^{24}$ Es de clima semiseco templado, con lluvias en verano cuya temperatura promedio es de $15^{\circ} \mathrm{C}$, la máxima de $18{ }^{\circ} \mathrm{C}$ en mayo y la mínima de $9.5^{\circ} \mathrm{C}$ en enero. En cuanto a la precipitación, ésta varía considerablemente según el relieve del municipio, pero el área de estudios es uno de los sitios donde la sombra pluvial de la Sierra Madre, al noreste, afecta más en combinación con una serie de cerros al este que corren de norte a sur, conocidos como Lomas del Zoquital, que son una segunda contención del poco aire húmedo que llega del Golfo. Así, pues, y tomando en consideración los años buenos y malos, la lluvia oscila en entre los 420 y $540 \mathrm{~mm}$, el mes de septiembre es el más lluvioso y enero, el más seco. ${ }^{25}$

Los cerros, lomas y barrancas donde se localizan las terrazas agrícolas forman una microcuenca que primero desaguan sus escorrentías

${ }^{24}$ Sauz Sabino, y sus dos barrios, al ser una población dispersa y estar en una topografía quebrada tiene distintas alturas sobre el nivel del mar. La que se indica señala la ubicación de la capilla y escuela primaria de la población, cuyas coordenadas son: $\mathrm{N}$ $20^{\circ} 21$ '13" у O 9846'20".

${ }^{25}$ Precipitación y probabilidad de lluvia en los estados de Querétaro e Hidalgo, Hidalgo, mapas 4, 5, 12 y 13 (México: unAM, Instituto de Geografía, Comisión de Estudios del Territorio Nacional, 1977). 
en un arroyo que sólo lleva agua durante el temporal, conocido como Arroyo Hondo y fluye del noroeste hacia el sur. Este desemboca en el río Amajac, donde se localiza el pueblo de Santa María Amajac. El ejido se extiende hacia el oeste, al otro lado de un par de montañas que se nombran El Tigre y El Águila, donde las barrancas tienen una pendiente grande, no cuentan con nombre y escurren el agua de lluvia en una profunda garganta por donde una vez más corre el río Amajac, que da infinidad de vueltas por la serranía, en parajes solitarios sólo transitados por cabras y uno que otro pastor.

La historia geológica del área se caracteriza por un pasado geológico donde el material sedimentario de origen calcáreo fue parte del lecho del mar. Los plegamientos son resultado, primero, en el Mesozoico, por la denominada Formación El Abra del Albiano-Cenomaniano que dio forma a un amplio segmento de la Sierra Madre Oriental; a ésta se sobrepone la Formación Soyatal del TuronianoSantoniano. En una segunda fase, ya en el Cenozoico, la Formación Atotonilco el Grande creó un paleolago en las inmediaciones del pueblo de Santa María Amajac que desapareció a consecuencia de un desplazamiento de masas que permitió la salida del agua al poniente de la cuenca y permite el cauce del río Amajac. ${ }^{26}$

Los suelos son muy delgados donde abundan el calcisol, material muy asociado a regiones áridas y semiáridas donde el sustrato original lo constituyen depósitos aluviales, coluviales o eólicos de materiales alterados, ricos en bases. También se encuentran en mayor abundancia los leptosoles, suelos poco profundos que recubren una roca continua o muy pedregosos con poca abundancia de materia orgánica. ${ }^{27}$

La vegetación característica es la de palmas (Brahea dulcis), nopales (Opuntia spp.), huizaches (Acacia schaffneri), yucas (Yucca filifera),

${ }^{26}$ Javier Arellano Gil et al., "Origen y características geológicas del paleo-Lago de Amajac, Hidalgo”, Revista Mexicana de Ciencias Geológicas 22(2) (2005): 200.

${ }^{27}$ María Patricia Velasco-de León y Erika Lourdes Ortiz-Martínez, "Nuevas especies de Quercus (Fagaceae) en el Plioceno de Santa María Amajac, Hidalgo, México”, Revista Mexicana de Ciencias Geológicas 27(2) (2010): 265-267. 
pequeñas comunidades de los nombrados candelabros (Pachycereus weberi), órganos (Pachycereus marginatus) y garambullos (Myrtillocactus geomertrizans), así como varias agavaceas que van desde el maguey cimarrón (Agave Salamina) del que sacan agua miel para hacer pulque, hasta grandes comunidades de ixtle (Agave lechuguilla), y que años atrás lo explotaban para hacer cordelería. También hay variedad de biznagas (Echinocactus spp, Ferocactus spp. y Melocactus $s p p$.) de esas que son chicas y apenas sobresalen del suelo, aunque de igual forma se pueden ver otras especies de tipo bulbosas de gran tamaño como la biznaga de acitrón (Ferocactus histrix). La presencia de algunos encinos (Quercus spp.) manifiesta la altura y, en algunas partes, pequeñas realmente, los pobladores han reforestado con algunos pinos piñoneros (Pinus cembroide), en lugar de la palma que es la comunidad vegetal más común.

Por lo que se refiere a los animales hay coyotes (Canis latrans), zorrillos (Mephitis macroura), cacomixtles (Bassariscus astutus), ardilla gris (Spermophilus variegatus), ratones de campo (Peromyscus sp.), conejo silvestre (Sylvilagus cuniculares), liebres (Lepus califomicus), distintas víboras y algunas lagartijas. Diferentes aves como zopilotes (Cathartes aura), gavilanes (Buteo sp.), primaveras (Turdus grayi), cardenales (Cardenales cardenales), gorriones (Passer sp.) y chuparrosas (Hylocharis leucotis) atraviesa sus cielos y anidan entre árboles, palmas y demás cactáceas. ${ }^{28}$ Los insectos también son abundantes, pero enumerarlos se sale de la intención de este ensayo, aunque no se niega su importancia en el ecosistema y los usos culturales que resultan de ellos.

\section{Terrazas en el Sauz Sabino}

Desde que los primeros pobladores de ejido del Sauz Sabino ${ }^{29}$ fueron trabajadores de la hacienda del Zoquital dedicados al cuidado

${ }^{28}$ Programa de manejo de la Biosfera Barranca de Metztitlán (México: Comisión Nacional de Áreas Protegidas, 2003): 27-47.

${ }^{29}$ Lo que a continuación se describe es el resultado de recorridos de campo, entrevistas con los seis informantes citados y de otras pláticas informales con campesinos de la zona de los que no se obtuvo su nombre por la inmediatez. 
Foто. Terrazas en el Sauz Sabino

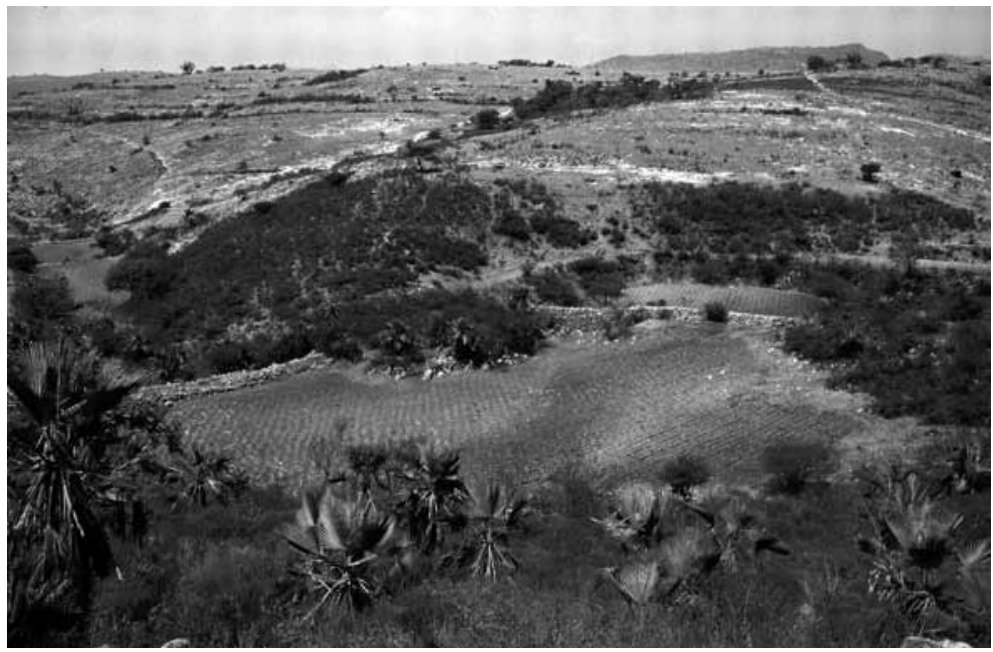

Fotografía de Ignacio Gutiérrez Ruvalcaba

de rebaños de cabras, y con seguridad desde tiempos inmemoriales, el medio ambiente de la zona ha estado sujeto a la constante intervención del hombre; primero con la caza y la recolección, luego con el pastoreo para llegar en el siglo pasado a la agricultura. Esto ha determinado un entorno completamente antropogénico, con una raíz histórica, y determinada por las necesidades cambiantes de sus pobladores en la región a través de los años. ${ }^{30}$

En este orden de ideas, las terrazas agrícolas, además de constituirse en una estrategia de producción, son por igual una arquitectura impuesta a la naturaleza por el hombre, un diseńo, por cierto, de gran belleza donde la formación de suelo agrícola; el manejo de la escasa agua de temporal; la construcción de paredones de piedras para formar las terrazas; y los cultivos en las parcelas dan forma al paisaje que llena los ojos cuando se contempla.

${ }^{30}$ Los pobladores no dan cuenta de asentamientos prehispánicos en tierras del ejido ni tampoco se encontraron durante los recorridos tepalcates, materiales líticos asociados con la actividad humana o algún tipo de estructura que de cuenta de ello. 
Dos tipos de terrazas coexisten en los terrenos del ejido: las que se pueden llamar de barranca, conocidas localmente como cajetes o jollas; $y$ las de ladera, que no tienen un nombre específico entre sus habitantes, pero hay quienes las nombran simple y sencillamente como terrazas o laderas agrícolas. Las primeras son las más productivas, las que año con año se siembran, ya que cada temporal, por malo que sea, se enriquecen por el arrastre de aluvión, conservan humedad residual y por su misma arquitectura forman suelos profundos. Las de ladera son pobres, de muy poca profundidad y en extremo pedregosas que obligan a los campesinos a sembrar un año sí y otro no, de acuerdo con la presencia o no de la lluvia.

Las terrazas de barranca se construyen atravesando con una hilera de piedras sobrepuestas, a manera de una barda seca, el lecho por donde van las escorrentías en las barrancas. Así, poco a poco, y en un proceso que puede tomar varios ańos, se van acumulando los aluviones y la materia orgánica por la acción física del arrastre y no sólo se deposita tierra, también hojas, ramas y pastos secos.

Originalmente, estas terrazas se comienzan a hacer con pequeñas represas de piedra que pueden medir entre 20 y $30 \mathrm{~cm}$ altura a todo lo ancho de la cañada y, según sean los temporales, se levantan colocando líneas de piedras una encima de otra conforme el aluvión rellena el espacio que queda entre el muro en construcción y la pendiente del lecho de la barranca, tanto en la línea perpendicular a las hileras de piedras que dan forma a la cortina o muro como en la horizontal que constituye la parcela. En la zona estos procesos pueden tomar varios años, hasta una década para formar una terraza de buen tamaño, considerando también la amplitud de la barranca pero, en realidad, esto es difícil de determinar debido a que el proceso está condicionado por las lluvias anuales y las dimensiones de cada cañada, junto con el área que se quiere llenar de aluvión para cultivo.

Según sea el caso, si el lecho es rocoso, la colocación de las piedras se hace sin más trabajo que el simple acomodo, pero si el cauce tiene algo de tierra, se hace un cimiento también de piedra para que la subsecuente colocación de piedras no sea socavada por el 
agua. En esta fase es muy importante la colocación de ramas de huizache, pencas de maguey y hojas secas de palma para que ayuden a retener el aluvión y no se corra el riesgo de que una avenida de agua, que no suelen ser fuertes en términos generales, se lleve todo el trabajo. ${ }^{31}$

Así construidas y consolidado el suelo profundo que es el sustrato para los cultivos, las dimensiones de las terrazas son muy variadas. Algunas tienen un área de apenas $20 \mathrm{~m}^{2}$, con un muro o cortina que alcanza tan sólo $1 \mathrm{~m}$ de altura por 3 de largo. Las más grandes en el ejido ocupan $6,500 \mathrm{~m}^{2}$, con una cortina de $68 \mathrm{~m}$ de largo y una altura entre 2 y $3 \mathrm{~m}$. No obstante, hay otras de $220 \mathrm{~m}^{2}$, con una cortina que alcanza hasta $4 \mathrm{~m}$ de alto y $12 \mathrm{~m}$ de largo. La pendiente y la amplitud de las barrancas es el factor que incide en las dimensiones de las terrazas de barranca.

Los elementos constructivos que los pobladores reconocen en cada una de las terrazas localizadas en las barrancas son el muro o cortina; el área de la parcela que es el suelo que se retiene, constituido de material aluvial; la alcantarilla o vertedera que es por donde fluye el exceso del agua de lluvia. Este último componente se encuentra en uno de los dos extremos laterales de la cortina y es resultado de la planeación arquitectónica de la parcela, donde cada una está ligeramente inclinada hacia uno de los lados, siguiendo la línea de los taludes que la circundan. El aspecto de este último elemento es el de una pequeña depresión en uno de los extremos laterales del muro. Se espera que con las pocas lluvias, las terrazas se encharquen, pero, debido a que el material aluvial de las terrazas es muy permeable, la absorción del agua es muy rápida, por lo que no perjudica la milpa y se beneficia por la cantidad de humedad que se almacena en el sustrato. De hecho, la mayoría de los muros tienen entre 15 y $25 \mathrm{~cm}$ más altura que el nivel de la tierra de la terraza, su finalidad es contener el agua e inundar la parcela, forma todo el conjunto una especie de caja que captura agua y aluvión. La cons-

${ }^{31}$ Desde inicios de los noventa del siglo pasado, los campesinos han observado que la lluvia, sin aumentar o disminuir de forma particular, es más común que caiga en forma torrencial, y no como lluvia prolongada de mediana intensidad a suave. 
trucción de la vertedera se planea de tal forma que el desagüe del líquido de cada terraza se verifique a partir de que el agua haya ya encharcado todo el terreno.

A lo largo del año, además de preparar el suelo para las siembras, los ejidatarios trabajan en grupos familiares, rara vez hay quien pague a un peón, realizan algunas labores de mantenimiento de los muros, alcantarillas y áreas de la parcela. Esto consiste en reparar, colocando piedras y tierra, la cortina de la terraza donde el agua ha erosionado y derrumbado parte de ésta. A la alcantarilla es necesario darle forma y pendiente adecuada para que la erosión no se convierta en un problema y provoque la destrucción de una parte del muro, además de propiciar el drenaje podando la vegetación que estorba. En la parcela, y debido a que el espacio agrícola conserva mayor humedad, el crecimiento de plantas y árboles en las orillas de forma natural es común y abundante, por lo que es necesario cortar, podar y acomodar con machete, hacha y azadón cada determinado tiempo. Muchos de estos huéspedes no son eliminados, ya que ayudan a que las escorrentías laterales no afecten por su fuerza a las terrazas, también porque de estas plantas se obtienen distintos productos de recolección como leña, miel de colmenas salvajes, quelites y frutos silvestres como el tejocote y el capulín. De igual forma en esa marańa que se forma en las orillas de las terrazas varios animales hacen sus madrigueras y se convierten en parte de la dieta de los pobladores al ser cazados, como sucede con liebres y conejos silvestres.

No hay terraza de barranca que se localice en el espacio de forma solitaria. Forman siempre conjuntos o series que van desde tres en una pequeña hondonada, hasta 52 en la cañada más grande. En términos lineales, hay conjuntos que tan sólo abarcan $60 \mathrm{~m}$ de largo, mientras que el más grande se extiende 4,745 m. Este hecho hace que estas terrazas sean un elemento ubicuo en el paisaje del ejido del Sauz Sabino, constituyen grupos de parcelas escalonadas que de forma descendente se ven entre lomas y cerros que, durante el temporal, se destacan por ser escalones verdes entre grandes espacios libres de vegetación o, cuando más, con pastos, piedras y pequeños bosques de huizaches y palmas. 
Existen un total de 405 terrazas de barranca que ocupan una superficie de 323 ha. ${ }^{32}$ Esto significa que el área ocupada por éstas corresponde a $13.98 \%$ del espacio total del ejido, el cual es de 2,310 ha. Son los terrenos más productivos que se siembran hasta que el temporal se ha iniciado, con la primera lluvia fuerte que empapa lo suficiente el suelo y sucede en junio o julio. Si en este par de meses no cae lluvia adecuada, no se corre el riesgo con la siembra.

Las terrazas de ladera son el otro tipo de estructuras que los pobladores del ejido han hecho para tener suelo agrícola, evitar la erosión y captar la poca humedad. Éstas se hacen siguiendo el contorno de los cerros y lomas, construyendo con piedras líneas paralelas que se distancian entre sí desde unos cuantos metros, hasta 50, esto depende de la pendiente. Ahí donde las lomas son casi planas estas terrazas pueden medir hasta $100 \mathrm{~m}$ de largo y estar separadas unas de otras por una distancia de varias decenas de metros. En cambio, en las laderas con mayor pendiente, las terrazas pueden tener de ancho 2 o $3 \mathrm{~m}$ y una longitud de $100 \mathrm{~m}$. Su construcción se hace mediante la organización de los grupos familiares.

La altura del muro que retiene la tierra puede ser de apenas $50 \mathrm{~cm}$, en tanto otras alcanzan el metro y medio. En algunos lugares donde se acumula la tierra, junto al muro, siembran magueyes cimarrones como sucede en muchas partes de la Meseta Central para reforzar la contención, pero esto no es una norma en los terrenos del ejido. Las parcelas formadas tienen suelos muy pedregosos, pobres en su sustrato, pero no dejan de ser parte de la estrategia adaptativa de los campesinos a la topografía del Sauz Sabino.

La combinación de terrazas de barranca con terrazas de ladera en sus flancos se puede observar en algunos puntos, incluso el escalonamiento entre unas y otras se confunde, por lo que en esas partes se hace difícil saber cuál es cual, pero esta situación sólo existe en cinco lugares específicos, que ocupan un área muy reducida. Lo que si es

${ }^{32}$ La determinación del área de las terrazas de barranca como las de ladera, se hizo por medio del análisis de la fotografía satelital de la aplicación de Internet Google Earth. Se complementó con recorridos de campo en los meses de diciembre de 2013, febrero y agosto de 2014 para ubicar en terreno las parcelas, además se contó con el censo de parcelas en poder del comisariado ejidal. 
recurrente es que la mayor parte de las viviendas están construidas sobre las terrazas de ladera, ocupan un espacio que puede variar según sea el tamaño del grupo familiar, ya que hay terrazas donde una familia nuclear construye dos unidades arquitectónicas, vivienda y cocina, mientras que una familia extensa puede ocupar de cinco a nueve unidades arquitectónicas.

Durante las secas se hacen las reparaciones pertinentes. Se levantan partes de los muros cuando han sufrido de erosión y se procura el cuidado de algunas árboles y plantas que den soporte a algunos puntos del muro, pero, es un hecho, que las terrazas de ladera tienen menos cuidados que las de barranca y, en este caso, para el drenado del agua no se hace ninguna obra en especial. El muro de contención de la terraza es lo suficientemente poroso como para que el agua trasmine y escurra.

El número de terrazas de ladera suman 211, cuya área total es de 297 ha, lo que equivale a 12.85 \% del total de las tierras del Sauz Sabino. Así, el ejido cuenta, considerando la suma de los dos tipos de terrazas, con 620 ha para uso agrícola, constituyen $26.83 \%$ de todo el espacio que posee la población y los barrios. Ahora, considerando sólo el área de las tierras agrícolas en los dos tipos de terrazas, resulta que aquellas que pueden ser sembradas ańo con ańo ocupan $52.09 \%$, mientras que el resto, $47.91 \%$, se siembran un ańo sí y otro no.

Este paisaje antropogénico también tiene asociada su apropiación por medio de la asignación nominal a las distintas series o agrupaciones de terrazas con nombres que las identifican en el contexto específico de los pobladores. Estas denominaciones se han establecido en función de la cercanía de grupos familiares, accidentes topográficos, caminos, árboles y hasta antiguos acontecimientos que marcaron el recuerdo de los pobladores. Por ejemplo, están las terrazas de los Hernández; de las peńas verdes; de la vereda del venado; del fresno de los González; la del horcado -en referencia a un suicidio ocurrido en los ańos cuarenta-; las de los novios; y otros semejantes. ${ }^{33}$

${ }^{33}$ Así lo refieren los señores Cayetano Jarillo y Maximino González. 


\section{LAS SIEMBRAS}

La milpa es la siembra tradicional que se realiza en los terrenos de las terrazas del ejido del Sauz Sabino y, en términos generales, el proceder en el cultivo es semejante en muchos aspectos a lo practicado en buena parte del Altiplano Central del país y del municipio, no obstante, hay algunas particularidades que aquí se describirán. Maíz, frijol de guía y calabaza son los tres productos que año con año se siembran, pero también hay quienes cultivan cebada y haba de forma alternada en la misma parcela o, un año, la triada de la milpa y, en otro, los otros dos cultivos. Las parcelas son labradas, según sea el tamaño de los terrenos, con arado tirado por bueyes o equinos, en pocas ocasiones, o con el palo plantador de punta metálica.

Las terrazas de barranca o las de ladera grandes, con un área agrícola de varios cientos o miles de metros cuadrados, se labran con yuntas. En las pequeńas, no mayores a los 1,000 $\mathrm{m}^{2}$, el trabajo se realiza con palo plantador o con una pala que en las ferreterías de la cabecera municipal denominan pala de ladera. ${ }^{34}$ En una y otra, el grupo familiar participa y sólo en algunas ocasiones, quienes pueden, pagan peones para hacer el trabajo.

Para no desperdiciar humedad en el sustrato, debido a la evaporación que ocasiona el voltear el suelo, no hay labor de barbecho en los meses de invierno y primavera por lo que es hasta el mes de junio cuando se inicia la siembra y con ello las labores. Donde se puede, con yunta se hacen los surcos de forma paralela al muro de las terrazas y en línea perpendicular a la dirección de las barrancas. Al paso del arado, con palo plantador, se hace un hoyo profundo, más hondo que en las tierras del altiplano, hasta llegar a la humedad residual que puede estar a los 25 o $35 \mathrm{~cm}$; ahí se colocan las semillas, tres de maíz, dos de frijol y dos de calabaza. En las terrazas pequeñas todo el trabajo se hace con palo plantador, sin ningún trabajo previo que afloje el suelo, colocando las semillas de la misma

${ }^{34}$ La pala de ladera tiene una cuchara pequeña, angosta y alargada de $25 \times 10 \mathrm{~cm}$, y un mango cuya longitud es de $180 \mathrm{~cm}$. 
manera que en las de mayor dimensión. De aquí en adelante y sin importar el tamańo de las parcelas, el deshierbe y aporque se realizan con machete y azadón de hoja metálica más pequeña que la utilizada en las partes llanas del municipio y del altiplano en general. ${ }^{35}$ En esta labor se tiene mucho cuidado de no maltratar el maíz, los retońos del frijol y la calabaza, esto sucede cuando las lluvias han empezado a caer de forma regular y las matas han crecido unos $40 \mathrm{o}$ $50 \mathrm{~cm}$ en el mes de julio o agosto, según el mes cuando se inició la siembra. El segundo deshierbe se hace también con el azadón, pero de igual forma con el machete, en el mes de agosto e incluso a inicios de septiembre.

Otro aspecto importante, distinto de la siembra en la zona, es la selección de la semilla de maíz, la que se nombra criolla y corresponde a la variedad nativa nombrada como maíz cónico. Los pobladores separan de forma muy marcada el maíz cultivado en las terrazas de barranca, de aquel que se usa para la siembra en las terrazas de ladera. La razón, según explican los campesinos, es que el sembrado en las de barranca ha desarrollado raíces más largas, que penetran más en el sustrato para alcanzar la humedad. Si se siembra maíz que se cultivó en las terrazas de ladera en una de barranca, la planta y el tamańo de la mazorca son menores y, por lo mismo, menor el rendimiento. Esto es muy importante para ellos y, cuando se hacen las cosechas entre diciembre y enero, es típico ver dos montones de mazorcas en los patios de las casas o en sus azoteas. Esto mismo sucede con el frijol, pero no con la calabaza. También es común el intercambio de semillas sembradas entre las familias en las terrazas de barranca, este canje ayuda al renuevo del material genético del maíz y a mantener la mayor productividad dentro de las distintas parcelas del ejido.

Es difícil establecer la productividad debido a la variación de diferentes factores. Arturo Warman señala que en el cultivo del maíz intervienen una serie de variables para que la producción sea óptima. Destaca que, si bien, es posible sembrarlo en regiones donde

${ }^{35}$ A este azadón en las ferreterías se le conoce como tomatero y su hoja es de un tercio que el azadón convencional. 
apenas se llega a los $250 \mathrm{~mm}$ de precipitación anual, ésta debe estar presente en los periodos críticos de su crecimiento, es decir, durante la germinación y desarrollo temprano y durante su floración, Si el agua falta en estos dos momentos o no es suficiente, la siembra fracasa, como también se arruina cuando no hay bastante insolación o se adelantan las heladas. ${ }^{36}$ En el área del Sauz Sabino, las condiciones medioambientales además de ser poco amables varían mucho año con año, como suele acontecer con la agricultura de temporal. En el ejido la insolación no es problema, las heladas se sufren, pero no son un fenómeno que a los campesinos les quite el sueño, debido a que su recurrencia no se considera grave y sí, en cambio, la irregularidad del temporal es una preocupación que se repite ańo con año. Ante este panorama la producción de maíz, en un año que se considera bueno, oscila entre 1,400 y $1,850 \mathrm{~kg} / \mathrm{ha}$, mientras que en los años malos, en los que si se pudo sembrar, va de los 650 a los $980 \mathrm{~kg} /$ ha. Con respecto al frijol, los datos para años buenos y malos fluctúan entre 540 y $620 \mathrm{~kg} / \mathrm{h}$ a para el primer caso, y entre 200 y 320 $\mathrm{kg} / \mathrm{ha}$ para el segundo.

Sin ser una práctica generalizada, es común encontrar en muchas terrazas de barranca la siembra de la calabaza que llaman chilacayota (Curcubita ficifolia). Ésta aprovecha los arbustos que se encuentran en las orillas de las parcelas para crecer, cubriéndolos según haya sido benigno el temporal, entre unos 20 a $35 \mathrm{~m}^{2}$. Su cultivo tiene dos funciones: primero como alimento; de ésta se hace a partir de noviembre la llamada calabaza en tacha, que se obtiene de cocerla a fuego lento con agua y mucho piloncillo. También se come troceada y acompaña varios guisos caldosos. Ya muy madura se consume su semilla, que es muy prolija, se come tostada. El segundo beneficio es que su guía al extenderse mucho sobre su soporte, como es el caso del huizache, evita que éste crezca en demasía y de sombra a las parcelas cultivadas, esta situación sin control provoca un crecimiento diferenciado del maíz.

${ }^{36}$ Arturo Warman, La historia de un bastardo: maiz y capitalismo (México: Fondo de Cultura Económica, 1988), 25. 
LOS POZOS DE AGUA

El agua es otro de los elemento escasos en el ejido del Sauz Sabino. Cuando sus antiguos pobladores eran pastores para la hacienda del Zoquital existía un pequeño manantial donde crecía un sabino, por ello el nombre, pero dejó de brotar agua en la década de los treinta del siglo pasado. En los ańos que manaba agua, apenas si era suficiente para las necesidades básicas de algunos habitantes por lo que, desde un principio, hubo la necesidad de obtener el preciado líquido de otra forma.

Desde que se tuvieron terrazas de barranca de tamańo suficiente para ser cultivadas, los campesinos del ejido percibieron, como una cualidad fundamental, que el suelo formado además de servir para la siembra de sus cultivos retenía buena cantidad de agua en el sustrato. Este hecho hizo que en diferentes puntos de la geografía de las terrazas de barranca construyeran pozos al pie de los muros de algunas.

Figura I. Perfil longitudinal de un grupo de terrazas de barranca

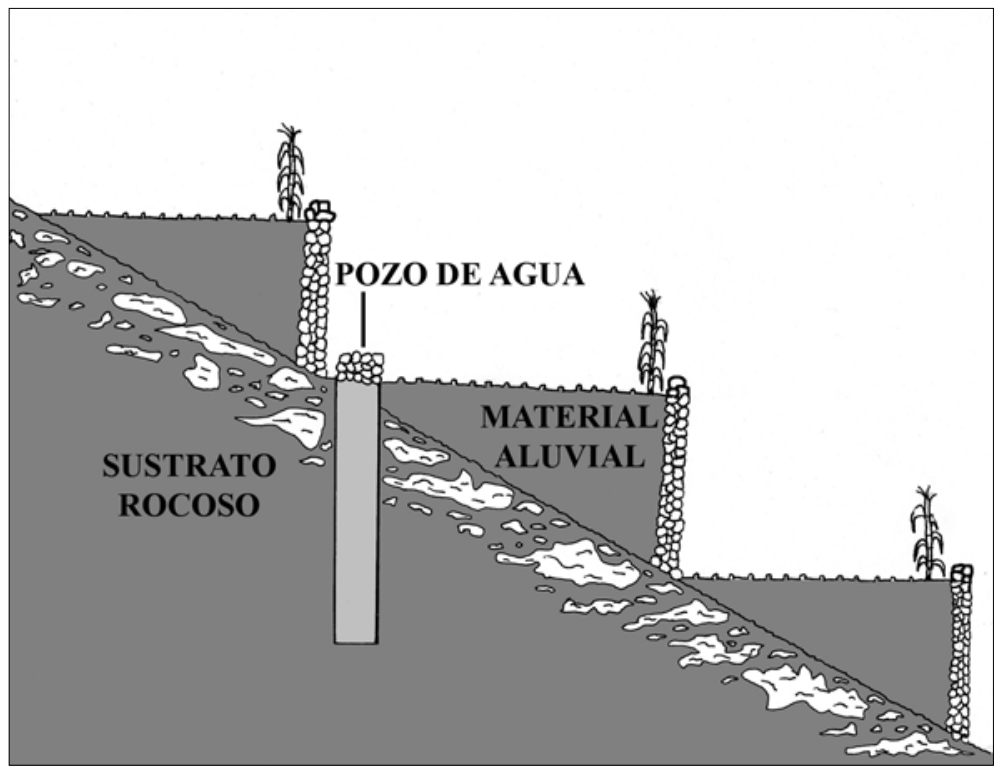


Estos pozos excavados en el suelo aluvial de los cajetes y en parte del lecho de roca caliza de los antiguos arroyos sobre los que se hicieron las terrazas, se excavan donde termina una y empieza otra. Funcionan como cisternas que se llenan de agua por filtración durante la temporada de lluvia, que se derrama por los brocales, todavía para finales del mes de febrero siguen teniendo agua. ${ }^{37}$ Su profundidad varía, ya que los hay de $6 \mathrm{~m}$ de profundidad, pero hay otros que llegan hasta $11 \mathrm{~m}$, se excava entre 5 y $10 \mathrm{~m}$ en la piedra del viejo cauce. La profundidad del pozo es determinado por la dimensión de la terraza. Pueden ser redondos, con un diámetro promedio de 1.50 $\mathrm{m}$, pero también los hay cuadrados con las mismas dimensiones por lado. Su construcción se hace reforzando los muros con piedra careada para evitar su derrumbe y azolve, se colocan las piedras con cuidado para que la filtración no se vea interrumpida. Cuentan con 17 pozos en total y sólo hay un caso donde se pueden ver dos en paralelo, a una distancia de $5 \mathrm{~m}$ uno del otro, junto a una terraza que ocupa un espacio de casi media hectárea y en el inicio de otra del mismo tamaño.

Los pozos tienen como principal uso ser una reserva de agua para los meses de sequía. A ellos acuden los pobladores con sus burros y bidones para llenar los envases y llevar el agua a sus casas para las actividades cotidianas. También mientras contengan agua es común hallar a señoras y jovencitas que lavan ropa junto a éstos, sobre piedras dispuestas para tal fin, se convierten en puntos de encuentro donde la socialización es una realidad de la vida diaria del ejido.

La construcción de estos pozos es colectiva, es decir, con la participación de los miembros activos del ejido en función de la vecindad. Cada trabajador lleva su herramienta para su construcción o para su desazolve, cuando esto es necesario y como parte del mantenimiento. Esto se hace periódicamente, ya que el descuido de esta actividad provoca que el pozo disminuya su capacidad de almacenamiento. Además de la limpieza se revisa el estado de las paredes y si hay daño se repara. Se ha podido registrar un caso donde el pozo se

${ }^{37}$ En años en que las lluvias fueron particularmente escasas, los pozos se han llegado a secar y, como consecuencia, algunos pobladores decidieron emigrar del ejido. 
derrumbó en su interior y se abandonó, pero a un lado de éste, se construyó otro nuevo.

Como las terrazas, los pozos también han sido nombrados e identificados como parte de la apropiación humana del entorno. Los nombres de los pozos son: De los Hernández, el Tejocote, El Capulín, Los Zorrillos, El Azul, Las Cabras, El Espino, Las Palmas, El Seco, El Turbio, Las Huilotas, El Xathe, Los Novios -son dos pozos contiguos-, La Víbora, El González y Pozo Hondo.

En el año de 2004 se comenzó a construir un acueducto por parte de los gobiernos del estado y municipal para abastecer de agua potable a este ejido y otros más dentro de una red que pretende satisfacer a varias localidades. En ese año, el agua sólo llegó a algunas casas de las población, las ubicadas más al sur. A principios del 2012 se termino la red y hoy la mayoría de las casas tiene agua entubada en sus domicilios. No obstante en la época de estiaje, en los tres ańos que han pasado desde su inauguración, el agua no ha sido suficiente, razón por la que se calendariza el abasto a lo largo de todos los beneficiarios de la red. Esta situación ha hecho que los pozos sigan vigentes; se cuidan en previsión de que el abasto municipal falle, pero, además, es un hecho que los pobladores más pobres, en su mayoría mujeres madres solteras, siguen sin contar con agua en sus casas por no poder pagar los derechos por el consumo del líquido y vivir en sitios más aislados, por lo que los pozos son la principal fuente de abasto de este pequeño grupo. También el agua es usada para las necesidades de los animales como burros, mulas, caballos, cerdos, una que otra vaca, bueyes, cabras, borregos y algunas aves de corral, todos criados a manera de complemento económico para la subsistencia y para ayuda en el trabajo.

Las reformas al artículo 27 de 1992 en lo referente a la propiedad de los ejidos han tenido como una de sus consecuencias que algunos pobladores vendan sus parcelas y se trasladen a vivir fuera del ejido. Ante esto, el primer resultado esperado es que algunas familias ahora tengan más tierras por compra que por dotación, pero, junto a ello, la idea de propiedad privada ha calado profundo en la mentalidad de algunos habitantes y han cercado algunas de las terrazas de barranca. Esto en sí mismo no es un problema, el conflicto surge 
debido a que estos propietarios al cercar sus parcelas bloquean el acceso a algunos pozos, tres para ser exactos, que se hicieron por participación colectiva, lo que da lugar a que también el agua de los pozos se vea como un bien particular en contradicción con lo colectivo, esta situación causa tensión y todavía está en entredicho la solución definitiva. Por el momento, en asamblea ejidal se ha decidido que de haber más ventas de parcelas, los pozos existentes no sean bloqueados, planteamiento que parece más idílico que realista mientras en la mentalidad de los campesinos se arraiga de forma más profunda el concepto de lo privado en oposición a lo colectivo.

\section{El Sauz Sabino en el espejo del Valle del Mezquital}

Las terrazas de barranca del Sauz Sabino son parte de una tradición que los hñäñu han llevado a la práctica desde tiempos inmemoriales en el Valle del Mezquital, de hecho este tipo de terrazas son parte de una técnica de herencia mesoamericana que no sólo este grupo étnico ha puesto en uso. Sólo en el valle de Nochixtlán, en la montañas de la Mixteca Alta, estado de Oaxaca, se ha hecho investigación, el dato arqueológico ha podido demostrar el uso de estas estructuras desde la fase Cruz, se localizan 51 sitios asociados a estas terrazas, con una temporalidad que va de 1,200 al 800 a. C. ${ }^{38}$ Asimismo el Cerro Jazmín, frente a la población de Yanhuitlán, en la misma Mixteca, fue ocupado por entero por una ciudad prehispánica; ahí se encontraron enterrados los muros y el material aluvial almacenado de un total de 11 sistemas constituidos por 114 terrazas, todas asociadas al periodo Posclásico. ${ }^{39}$

El Valle del Mezquital se encuentra al poniente de los terrenos del ejido del Sauz Sabino a una distancia en línea recta de tan sólo $11 \mathrm{~km}$, del otro lado de la prolongación serrana del Eje Neovolcáni-

${ }^{38}$ Ronald Spores, "Settlement, Farming Technology, and Environment in the Nochixtllan Valley”, Science 166(3,905) (octubre 1969): 559-561.

${ }^{39}$ Verónica Pérez Rodríguez, Investigaciones en Cerro Jazmin: un estudio sobre urbanismo y el paisaje aterrazado de la Mixteca Alta, Oaxaca. Informe técnico final temporadas 2008-2009 (Flagstaff: Northern Arizona University, Departament of Anthropology, 2009): 17 y $42-69$. 
co, luego de saltar la profunda garganta por donde corre el río Amajac y las agrestes barrancas que desaguan sus escorrentías en éste, montañas que dan forma a los contrafuertes que descienden de esta formación montańosa y de la Sierra Madre Oriental que, juntas, delimitan este gran valle en su porción noreste.

Los arqueólogos que han estudiado el Valle del Mezquital afirman que el uso de las terrazas de barranca y de ladera en la agricultura indígena prehispánica fue un recurso técnico no excepcional, no obstante, falta investigación arqueológica que confirme tal presunción. Este hecho parece factible debido a que su uso actual es extenso en la parte del valle, arriba indicada, área donde se localiza el mayor número de hablantes de hñäñu y que, en combinación con las condiciones medio ambientales de poca agua y falta de suelos agrícolas son comunes, por lo que las terrazas de barranca y ladera se han desarrollado ampliamente junto con otras que se denominan atajadizos. $^{40}$

Las terrazas de barranca se localizan en este valle, según datos de Emmanuel Galindo, en los municipios de San Agustín Tlaxiaca, El Arenal, Actopan, Santiago de Anaya, Ixmiquilpan y Cardonal. ${ }^{41}$ Hay que agregar, por trabajo de campo realizado, que su presencia también es abundante en los municipios de Tasquillo y Zimapán. Actualmente, varias de estas jurisdicciones cuentan con la mayor concentración de hablantes indígenas hñänu u otomí en el Valle del Mezquital y preservan sustancialmente las tradiciones culturales de estos pobladores originarios. Así, Actopan tiene $16 \%$ del total de su población que habla esta lengua; El Arenal, 5.5\%; el Cardonal, 82 \%; Ixmiquilpan, $70.2 \%$; San Agustín Tlaxiaca, 1.7 \%; Santiago de Anaya, $85.8 \%$; Tasquillo, $67.6 \%$; y Zimapán, $27.9 \% .{ }^{42}$

${ }^{40}$ Fernando López Aguilar, Simbolos del tiempo. Inestabilidad y bifurcaciones en los pueblos de indios de Valle del Mezquital (Pachuca: Consejo Estatal para la Cultura y las Artes, 2005), 37-39. Fernando López Aguilar y Patricia Fournier, "Espacio tiempo y asentamientos en el Valle del Mezquital: un enfoque comparativo con los desarrollos de William T. Sanders", Cuicuilco 16(47) (septiembre-diciembre 2009), 117.

${ }^{41}$ Emmanuel Galindo Escamilla, "Captación de agua y retención de suelos en jollas en el parte aguas de las cuencas de los ríos Actopan y Amajac", Boletín del Archivo Histórico del Agua, año 13(número especial) (2008): 18.

${ }^{42}$ Enrique Serrano Carreto, Arnulfo Embriz Osorio y Patricia Fernández Ham, 
En 1977, Kirsten Johnson reporta que estas terrazas se hacían en los terrenos más áridos del valle, como respuesta de la tradición agrícola de los hñäñu a las condiciones medio ambientales. Además de las terrazas de barranca, esta investigadora ha descrito ampliamente las nombradas atajadizos; terrazas, según ella, más complejas que se construyen a la vera de un arroyo, que la mayor parte del año está seco. Cuando llueve la corriente de estos arroyos generalmente no es torrencial, apenas un escurrir de agua que los campesinos conducen, por medio de pequeñas presas derivadoras hechas de piedra y arena, a la parcela de la terraza, diseñada como una caja para la captura del agua y sedimento. En estas terrazas las plantas más cultivadas son maíz y frijol; el maguey es también una planta fundamental dentro de la arquitectura de la terrazas y su cultivo se hace a un lado de donde se encuentra el muro de piedras y tierra que forma la caja, muro que puede ser doble y acompańado de aluvión que rellena el espacio existente entre las dos estructuras de piedra. ${ }^{43}$

Las terrazas de barranca en el valle del Mezquital son conocidas también como cajetes, presas de barranca, presas para milpa, presillas y atajadizos de cajete; en hñänu los términos que se pudieron compilar son: juxdo mahmi (cerca de piedras de cajete); juxhuähi mahmi (terreno para cercar milpas de cajete); juxhuähi xahai (terreno húmedo para cercar milpas).

En cuanto a su arquitectura, sus componentes son el muro, generalmente de piedra o de doble muro cubierto con tierra; la puerta o desagüe que es por donde sale el exceso de agua de la terraza y aluvión, que evita la erosión de los muros; los desagües son pequeñas acequias hechas de forma muy rudimentaria en paralelo a los taludes de las barrancas y que funcionan para dar control a la esco-

coords., Indicadores socioeconómicos de los pueblos indígenas de México, 2002 (México: Instituto Nacional Indigenista, Programa de las Naciones Unidas para el Desarrollo, 2002), 88-89.

${ }^{43}$ Kirsten Johnson, "Desintegration of tradicional resources-use complex: The Otomí of the Mezquital Valley, Hidalgo, México", Economic Geography 53(4) (octubre 1977): 364-365. Este tipo de terrazas también se han estudiado desde la óptica de la etnoedafología: Diódoro González Sánchez, Georgina F. López Ríos y Juan Hernández Hernández, "Agricultura ñhañhu-otomí del valle del mezquital, Hidalgo", Terra Latinoamericana 22(1) (enero-marzo 2004): 117-126. 
rrentía que baja por los taludes que contienen las terrazas. Estos canales pueden estar o no, muchos de ellos se hacen en función del temporal y la fuerza de las lluvias que acontecen cada año.

Una característica muy recurrente de las terrazas de barranca del Valle del Mezquital es que, conforme se desciende del pie del monte hasta llegar a los abanicos aluviales que forman las cañadas al llegar al valle, éstas se trasforman paulatinamente en terrazas de ladera, luego al seguir descendiendo se convierten en terrazas de valle y todas juntas dan forma a un paisaje antropogénico muy característico de la región, todo escalonado que cubren grandes extensiones a lo largo y ancho de la parte norte y noroeste del Valle del Mezquital.

En cuanto a los pozos de agua sólo se pudieron hallar quince semejantes a los descritos para el municipio del Sauz Sabino, no obstante, algunos campesinos recuerdan que éstos eran más comunes hace ya algunas décadas. Los encontrados se ubican en los municipios de Cardonal, siete; Ixmiquilpan, tres; Santiago de Anaya, tres; y Tasquillo, otros dos. Todos en sitios muy aislados, alejados de todo camino terracero y usados fundamentalmente para dar agua al ganado. Cabe señalar que no se hizo un recorrido sistemático que permitiera hacer un censo detallado de este tipo de depósitos.

\section{Conclusión}

Con lo hasta aquí expuesto es importante subrayar cómo el uso de técnicas agrícolas se conserva en los grupos humanos cuando existen circunstancias específicas. En este caso, un grupo de campesinos de origen hñänu que, para finales del siglo XIX y por razones de subsistencia, se dedicaba a la atención de ganado caprino, práctica que no es ajena a este pueblo originario desde el siglo XVI, para luego retomar su conocimiento tradicional sobre agricultura cuando las condiciones sociales se transformaron. Los pobladores del Sauz Sabino son partícipes de una tradición indígena adaptada a las condiciones de tierras semiáridas, dedicados a la agricultura de temporal y limitados por la escasa precipitación. El resultado es el desarrollo de un sofisticado conocimiento y manejo de los suelos; hace que la erosión se convierta en su aliada; manipula el acarreo natural de estos mate- 
riales; y dirige su acumulación para formar tierras agrícolas construidas con el propósito de aprovechar al máximo la humedad residual para sus cultivos y obtener una reserva de agua para los meses de mayor necesidad. ${ }^{44}$

Esta práctica ancestral no es exclusiva de Mesoamérica, su importancia en otras regiones es igualmente reconocida como invención que tuvo origen en distintos lugares. La conformación de terrazas en las regiones semiáridas de los andes peruanos, o los bancales de la costa que se extiende entre Málaga y Almería, en España, son dos ejemplos, tan sólo, que en su devenir histórico expresan, en lo tocante a su adaptación a las condiciones topográficas y medio ambientales, un profundo conocimiento de la dinámica hidrológica superficial que afecta laderas, lomas y cerros, para captar los sedimentos que forman suelo agrícola y aprovechar al máximo la poca agua disponible. ${ }^{45}$

\section{Hemerografía}

\section{Diario Oficial de la Federación \\ Periódico Oficial del Gobierno del Estado de Hidalgo}

\section{BibLIOGRAFíA}

Arellano GiL, Javier et al. "Origen y características geológicas del paleo-Lago de Amajac, Hidalgo". Revista Mexicana de Ciencias Geológicas 22(2) (2005): 199-211.

${ }^{44}$ Víctor M. Toledo y Narciso Barrera-Bassols, "Saberes tradicionales y adaptaciones ecológicas en siete regiones indígenas de México”, en Saberes ambientales campesinos. Cultura y naturaleza en comunidades indígenas y mestizas de México, coord. Felipe Reyes Escutia y Sara Barrasa García, 32-38. Tuxtla Gutiérrez: Universidad de Ciencias y Artes de Chiapas, 2011.

${ }^{45}$ Ann Kendall y Gerard den Ouden, "Terrazas una infraestructura agrícola como contribución a las estrategias de manejo de riesgos climáticos", en XII Congreso de Historia Agraria. Córdoba, Ministerio de Educación y Ciencia, Junta de Andalucía, Diputación de Córdoba, Universidad de Córdoba, seHA, Grupo de Historia Social Agraria, 2008, 7-9. http://bibliotecavirtual.minam.gob.pe/biam/handle/minam/1715 (Fecha de consulta: 9 de marzo de 2016). 
Ballesteros G., Víctor Manuel. "La hacienda de San Nicolás Amajac del siglo Xvi al xx". En Origen y evolución de la hacienda en México, ed. María Teresa Jarquín, 81-84. Toluca: El Colegio Mexiquense, 1990.

Galindo Escamilla, Emmanuel. "Captación de agua y retención de suelos en jollas en el parte aguas de las cuencas de los ríos Actopan y Amajac". Boletín del Archivo Histórico del Agua, año 13(número especial) (2008), 17-20.

González Sánchez, Diódoro, Georgina F. López Ríos y Juan Hernández Hernández. "Agricultura ñhañhu-otomí del valle del mezquital, Hidalgo". Terra Latinoamericana 22(1) (eneromarzo 2004): 117-126.

Hernández Mogica, Javier. Organización campesina y lucha agraria en el Estado de Hidalgo, 1917-1940. Pachuca: Universidad Autónoma del Estado de Hidalgo, 2000.

Herrera Cabañas, Arturo. Los movimientos campesinos en el Estado de Hidalgo, 1850-1876. Pachuca: Gobierno del Estado de Hidalgo, 1995.

Johnson, Kirsten. "Desintegration of Tradicional Resources-Use Complex: The Otomí of the Mezquital Valley, Hidalgo, México". Economic Geography 53(4) (octubre 1977): 364-367.

Kendall, Ann y Gerard den Ouden. “Terrazas una infraestructura agrícola como contribución a las estrategias de manejo de riesgos climáticos”. En XII Congreso de historia agraria. Córdoba: Ministerio de Educación y Ciencia, Junta de Andalucía, Diputación de Córdoba, Universidad de Córdoba, seHA, Grupo de Historia Social Agraria, 2008. http://bibliotecavirtual.minam.gob.pe/biam/ handle/minam/1715 (Fecha de consulta: 9 de marzo de 2016).

López Aguilar, Fernando. Simbolos del tiempo. Inestabilidady bifurcaciones en los pueblos de indios de Valle del Mezquital. Pachuca: Consejo Estatal para la Cultura y las Artes, 2005.

López Aguilar, Fernando y Patricia Fournier. "Espacio tiempo y asentamientos en el Valle del Mezquital: un enfoque comparativo con los desarrollos de William T. Sanders". Cuicuilco 16(47) (septiembre-diciembre 2009): 113-146.

Pérez Rodríguez, Verónica. Investigaciones en Cerro Jazmin: un 
estudio sobre urbanismo y el paisaje aterrazado de la Mixteca Alta, Oaxaca. Informe técnico final temporadas 2008-2009. Flagstaff: Northern Arizona University, Departament of Anthropology, 2009.

Precipitación y probabilidad de lluvia en los estados de Querétaro e Hidalgo. México: unam, Instituto de Geografía, Comisión de Estudios del Territorio Nacional, 1977.

Programa de manejo de la Biosfera Barranca de Metztitlán. México: Comisión Nacional de Áreas Protegidas, 2003.

Serrano Carreto, Enrique, Arnulfo Embriz Osorio y Patricia FERnández Ham, coord. Indicadores socioeconómicos de los pueblos indigenas de México, 2002. México: Instituto Nacional Indigenista, Programa de las Naciones Unidas para el Desarrollo, 2002.

Spores, Ronald. "Settlement, Farming Technology, and Environment in the Nochixtllan Valley". Science 166 3,905$)$ (octubre 1969): 557-569.

Toledo, Víctor M. y Narciso Barrera-Bassols. "Saberes tradicionales y adaptaciones ecológicas en siete regiones indígenas de México", en Saberes ambientales campesinos. Cultura y naturaleza en comunidades indígenas y mestizas de México, coord. Felipe Reyes Escutia y Sara Barrasa García. Tuxtla Gutiérrez: Universidad de Ciencias y Artes de Chiapas, 2011.

Velasco-de León, María Patricia y Erika Lourdes Ortiz-MartíNEZ. "Nuevas especies de Quercus (Fagaceae) en el Plioceno de Santa María Amajac, Hidalgo, México". Revista Mexicana de Ciencias Geológicas 27(2) (2010): 264-277.

Warman, Arturo. La historia de un bastardo: maiz y capitalismo. México: Fondo de Cultura Económica, 1988. 